\title{
Coral hydroxyapatite versus tricalcium phosphate $\beta$ in sinus augmentation: A comparative clinical study
}

\section{Original Article}

\author{
Salem A. Waly \\ Department of Oral and Maxillofacial Surgery, Faculty of Dental Medicine, \\ Al-Azhar University, Cairo, Egypt
}

\begin{abstract}
Background: Choosing augmentation equipment is a critical factor in maxillary sinus augmentation. The choice of one of these materials for sinus augmentation remains controversial.

Purpose: The aim of this clinical study was to compare the biological performance of the new coral hydroxyapatite (CHA) graft material and the synthetic material made from tricalcium phosphate (b-TCP) in sinus augmentation.

Materials and Methods: The study consisted of 20 patients (10 men and 10 women) who were edentulous or partially edentulous in the posterior maxilla and required the placement of implants. A total of (20) sinus transplants were performed in a single step using implant installation procedures. CHA was used in 10 patients and b-TCP in 10 patients.

Results: An average increase in the height of the mineralized tissue of $7.1 \pm 1.1 \mathrm{~mm}$ in the b-TCP group and $4.6 \pm 1.17 \mathrm{~mm}$ in the CHA group was when comparing the preoperative CT scan with that after 9 Months. After the maxillary sinus augmentation procedure. The average percentage of the density of the transplanted area after 9 months, based on the initial alveolar ridge density at the implantation site, was $63.6 \%$ and $-2.89 \%$ for the b-TCP group and the CHA group $(P<0.001$ and 0.373$)$ respectively.

Conclusion: Both graft materials showed successful biocompatibility and osteoconductivity in sinus augmentation. However, B-TCP appears to be more effective than CHA in osteoconduction.
\end{abstract}

Key Words: Bone density, Coral hydroxyapatite, Sinus augmentation and Tricalcium phosphate.

Received: 18 April 2020, Accepted: 07 June 2020.

Corresponding Author: Salem A. Waly, Department of Orthodontics, Faculty of Dentistry, Al-Azhar University, Cairo, Egypt, Telephone: +2 0222629412, Mobile:+966560943242, E-mail: salemwaly2006@yahoo.com.

ISSN: 2090-097X, January 2020, Vol. 11, No. 1.

\section{INTRODUCTION}

Boyne and James ${ }^{[1]}$ introduced the sinus elevation procedure in the early 1980 s to overcome the anatomical limitation and to achieve vertical bone height in the atrophic areas of the posterior maxilla to facilitate the insertion of dental implants. This procedure contributed significantly to the use of dental implants. Although lifting the sinus membrane is a relatively safe pre-prosthetic surgery, there are some potential problems associated with the technique. Placing the implant in the posterior maxilla often requires surgery in the subantral area because the bone volume is insufficient.

Tatum $^{[2]}$ described the enlargement of the maxillary sinus for the insertion of implants in this region for the first time. This surgical procedure allows the implant to be placed by increasing the height of the alveolar bone in this area. A variety of graft materials have been used to enlarge the bottom of the maxillary sinus. Autogenic bone grafts are considered the gold standard because they are not immunogenic and have osteogenic, osteoinductive and osteoconductive properties ${ }^{[1,3-6]}$. However, there are several disadvantages, including donor site morbidity, lameness when the graft is removed from the iliac crest, prolonged healing time, second surgery, the need for general and hospital anesthesia, higher treatment costs, and unpredictable absorption of the $\operatorname{graft}^{[7,8]}$.

These disadvantages have led to the search for suitable graft materials, which are a biocompatible, and osteoinductive or at least osteoconductive alternative to autogenous bone replacement in the procedure for enlarging the sinus floor. Various bone graft materials such as alloplastics (hydroxyapatite, b-tricalcium phosphate and bioactive glass) $)^{[9-14]}$, xenografts (bovine or coral hydroxyapatite) $)^{[15-20]}$, or allografts (freeze-dried demineralized bone $)^{[21]}$ are currently in use as an alternative or supplement to autogenous bone. These biomaterials serve as a scaffold for additional bone formation. However, bone reconstruction is slower than with autogenous bone $\operatorname{grafts}^{[22]}$.

Coral hydroxyapatite (CHA), a type of xenograft, has proven to be a safe and biocompatible bone graft material with osteoconductive properties ${ }^{[23-25]}$. In addition, several experimental and clinical studies have shown positive results with CHA graft materials in augmentation of the maxillary sinus floor ${ }^{[22]}$.

Another popular graft material that has shown promising results with osteoconductive properties is beta- 
tricalcium phosphate (b-TCP), a ceramic alloplastic ${ }^{26-28]}$. Several authors have reported that b-TCP is a satisfactory graft material for increasing the maxillary sinuses ${ }^{[11-14,22]}$. The choice of augmentation material is a crucial factor in sinus augmentation. Choosing one of these materials for maxillary sinus augmentation remains controversial and no consensus has yet been reached.

The aim of this clinical study was to compare the biological yields (quantity and density) of the new CHA graft material with the synthetic b-TCP material, in patients with simultaneous atrophic maxillary sinus augmentation and implantation.

\section{MATERIALS AND METHODS}

The study consisted of 20 patients $(10$ men and 10 women) who were edentulous or partially edentulous in the posterior maxilla and required the placement of implants. The mean age of the patients was $41.8 \pm 12.5$ years (range: 25 - 63 years).

The main criterion for admission to the study group was a residual alveolar ridge height of $5-6 \mathrm{~mm}$ and a width of 68- mm. Panoramic X-rays and computed tomography (CT) were taken from the patients. These $\mathrm{x}$-rays were used to assess the width and height of the remaining alveolar ridge (Figure 1). The surgical phase was planned as a sinus augmentation procedure in connection with the placement of the implant.

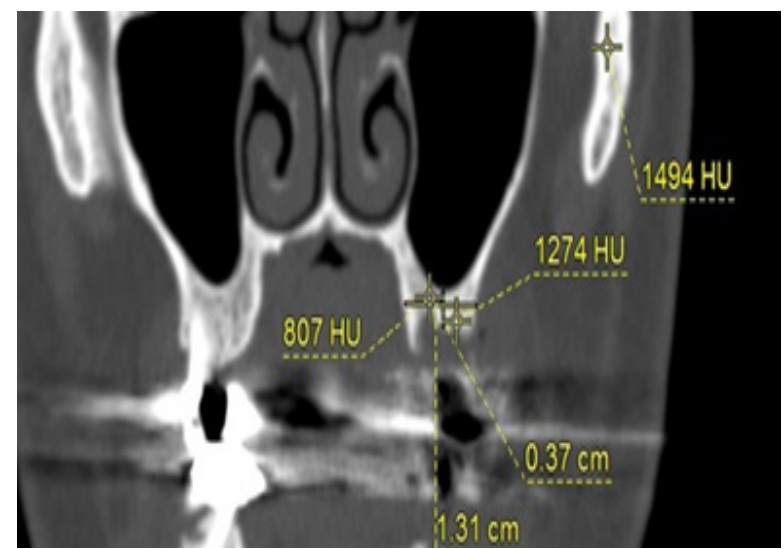

Figure 1: Representative pre-surgical CT scan section from the right maxillary area of patient (coronal section).

The patient exclusion criteria were poor oral hygiene, intensive smoking (approx. 15 cigarettes / day), uncontrolled diabetes mellitus or other systemic diseases and acute maxillary sinus infection. All patients were in good health and without any disease that could affect the outcome of the treatment. Patients were fully informed about the procedures including operations, transplant materials and implants. Written and informed consent was obtained. The research protocol has been approved by the Ethics Committee of the Faculty of Dentistry.

\section{Sinus floor augmentation}

Twenty single-stage sinus augmentation with simultaneous implantation were performed under local anesthesia ${ }^{[3]}$. Patients received antibiotics as $1 \mathrm{~g}$ of amoxicillin for prophylaxis 1 hour before surgical exposure of the sinus floor. A crestal incision was made slightly palatally throughout the edentulous area. Vertical release cuts were made at the front and back. A mucoperiosteal flap was then raised, which allowed easy access to the lateral wall of the maxillary sinus. A lateral maxillary antral window was made by a round diamond mill with continuous cooling using a sterile saline solution.

After the Schneiderian, membrane was exposed, the mouth window slowly moved to the medial side of the chest. Using sinuses of different shapes and sizes, the sinus membrane gradually separated.

The sinus membrane was protected during the preparation of the implantation site. With the help of the surgical stent, a pilot drill was used to determine the position of the implant in the alveolar ridge. The implantation site was expanded with conical osteotomes. By using the smallest osteotome for the first time, followed by ever-larger osteotomes, the diameter of the implant site became slightly smaller than that of the implant. The osteotome technique was used to increase the bone density around the implant site and to support the stability of the primary implant ${ }^{[10]}$.

The space created between the maxillary alveolar ridge and the sinus floor was filled with $2.5-3 \mathrm{~g} \mathrm{CHA}$ (Via San Benedetto, 1837-40018 San Pietro in Casale BO Italia) or $2.5-3 \mathrm{~g}$ b-TCP (Sunstar Americas, Inc., formerly John O. Butler Company). The choice of whether the maxillary sinus would contain the CHA test substance or the b-TCP load was made at random distribution (Figure 2).

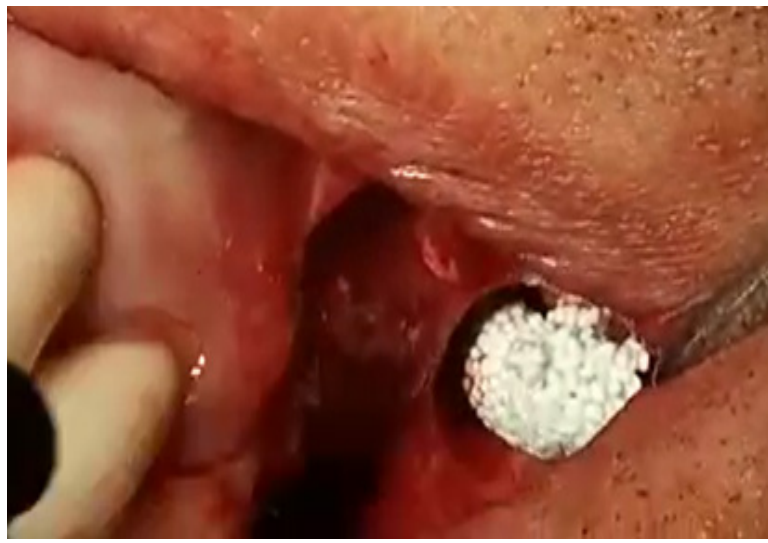

Figure 2: The space created between the maxillary alveolar process and the sinus floor was filled with $\mathrm{b}-\mathrm{TCP}$

The study population was originally planned with 24 patients (12 patients per group). The patients were 
randomly divided into one of two groups according to the order of admission. However, in the b-TCP group, two patients were lost during the follow-up and two patients disagreed with postoperative computed tomography in Group 1, and CHA was used for the 10 patients ( 5 men) and (5 women). While Group 2, b-TCP was used as a graft material for maxillary sinus augmentation.

All transplant materials were mixed with blood from the surgical site before they were placed in the open sinus cavity. No membrane was used to cover the lateral window. Complete wound closure was achieved with 30/ resorbable sutures (Ethicon US, LLC. 2017. 085133 - 171129).

\section{Postoperative care}

Patients were advised not to wear their prosthesis 2 to 3 weeks after surgery until the prosthesis was covered with a soft lining (Sofreliner S, Tokuyama Corp., Tokyo, Japan). Antibiotics (1 g clavulanic amoxicillin twice daily) were prescribed for 10 days and pain relievers as needed. Chlorhexidine gluconate $0.12 \%$ mouthwash (3M, ESPE, Peridex and PerioMed are registered trademarks of $3 \mathrm{M}$ or $3 \mathrm{M}$ Deutschland $\mathrm{GmbH}$.) Twice a day for 1 week for all patients. The sutures were removed 2 weeks after the operation.

Patients with sinus perforation identified during surgery received decongestants 1 week after surgery. Patients who experience symptoms of congested nose or have had a common cold were advised not to travel by plane until the symptoms have resolved. Postoperative visits were scheduled monthly to review the healing process. After an average healing of 10.5 months (range: 9 - 12 months), the inserts of 50 implants were as follows: 30 implants at the CHA site and 20 implants in the b-TCP site. The second surgical step was done 9 months later. A full ceramic crown was then placed. The 2-year follow-up showed no signs or symptoms of implant failure (Figure 3 ).

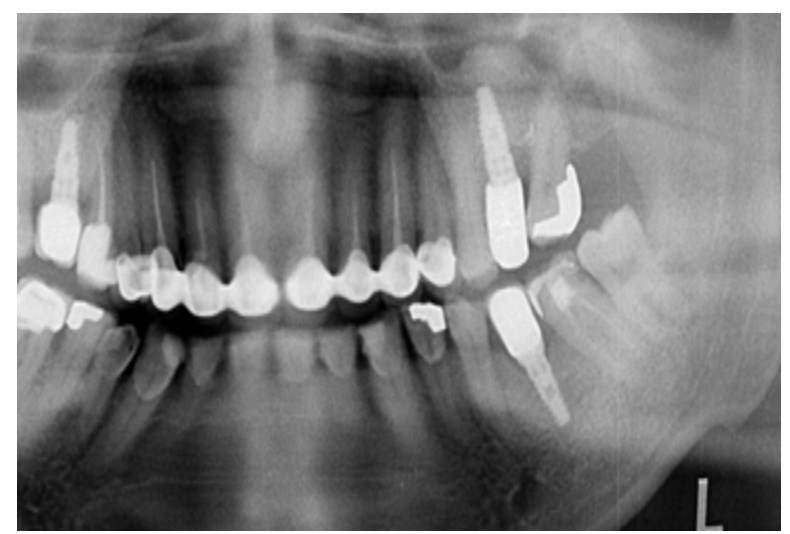

Figure 3: 2-year post-operative follow-up examination showed no signs or symptoms of implant failure.
The CT scans were recorded before surgery (Figure 1), immediately after surgery and 9 months after surgery (Figure 4) and analyzed with the RIS-PACS software by an experienced radiologist who was unfamiliar with the surgery and the distribution of each biomaterial to assess the height of the ridge and changes in the density of the bone substitute material in the sinus cavity.

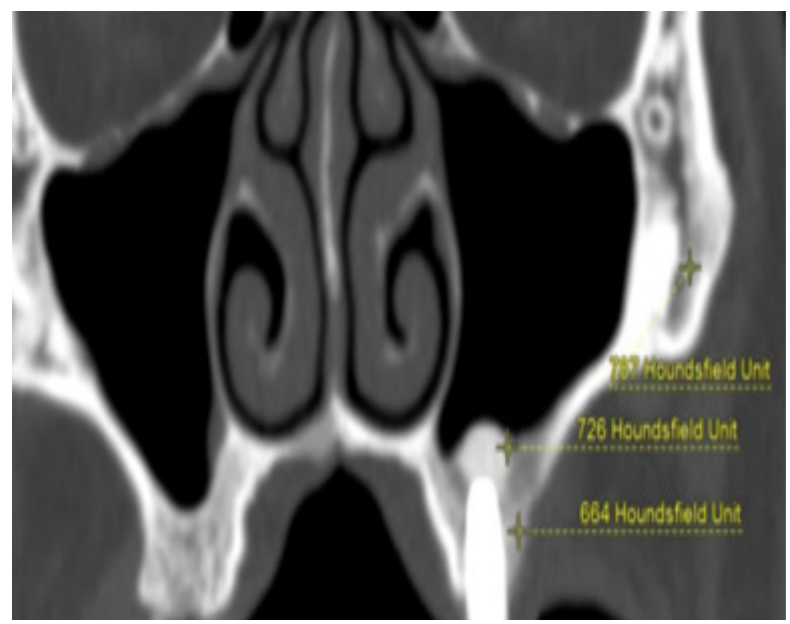

Figure 4: Post-treatment CT scan section obtained at the same surgical site.

\section{Radiographic analysis}

\section{Radiographic images}

The images were taken for preoperative diagnosis and planning immediately after augmentation with implant insertion and postoperative sinus augmentation by 9 months using standardized low-dose computed tomography (Sensation 16 and Volume Zoom, Siemens) (Healthcare, Erlangen, Germany) and an effective dose of $110 \mathrm{~mA}$. The following parameters were used: tube voltage: $120 \mathrm{kV}$, sampling time: 3 to $10 \mathrm{~s}$, layer thickness: $2 \mathrm{~mm}(0.75 \mathrm{~mm})$ with sagittal and coronal reconstruction and table movement / inclination: 0,9 .

\section{Analyzing software}

The CT scans were analyzed using the RIS-PACS AW Suite 2.0 software (General Electric Healthcare, Chalfont St. Giles, UK) to determine the dimensions and density of the ridge before and 9 months after insertion of biomaterials and the Implantation. RIS-PACS software system is suitable for viewing and processing multidimensional images of various devices (tomosynthesis by magnetic resonance, $\mathrm{CT}$ etc.) and enables the analysis and processing of images in DICOM format.

First, the images, data and names of the patients were anonymized to ensure an objective and blind analysis. The 
software shows computer tomography in three different projections (coronal, axial and sagittal) as a series of twodimensional sections, depending on the thickness of the section. In addition, a three-dimensional scan could be generated from the various two-dimensional slides.

In the present study, based on the multitude of software tools, the "density measurement" was used to assess the change in the density of the directly elevated materials and 9 months after sinus augmentation. In addition, the increase in the density of the bone substitute material and the initial density of the initial ridge (reference bone) were analyzed with the software tool "density measurement" (Figure 3).

The analysis of the amount and density of the graft using the above software was carried out as follows: An area was marked in the transplanted bone substitute material and in the reference bone of the original ridge to measure the graft. Comparison of the initial CT scan of the initial ridge density with that obtained immediately and 9 months after the operation revealed a quantitative and qualitative assessment of the newly formed mineralized tissues in the sinus cavity.

\section{Statistics}

Statistical analysis was performed with the software package SPSS version 25.0 (IBM SPSS Statistics for Windows, version 25.0. Armonk, NY: IBM Corp., USA). Mean $\pm \mathrm{SD}$, minimum and maximum for quantitative variables were used for descriptive statistics. For analytical statistics: the t-test of independent samples was used to assess the differences in the means of the quantitative variables between the two groups, while the t-test of the matching samples was used to compare the means of the quantitative variables within from the same group. Statistical methods were verified in which a significant value of $p<0.05$ and a very significant value of $p<0.001$ were assumed.

\section{RESULTS}

(Table 1) shows a detailed assignment of the number and positions of the implant, on the other hand the data on the patient population, the length of the healing period, changes in bone height in enlarged sinus in the base given in the tables (2a, 2b, 3a, 3b, 3c, 4a, 4b).

Table 1: Detailed overview of the number and sites of placed implants in the CHA, bTCP sinus augmented regions:

\begin{tabular}{ccccc}
\hline \multirow{2}{*}{$\begin{array}{c}\text { Number of } \\
\text { patients }\end{array}$} & \multicolumn{2}{c}{$\begin{array}{c}\text { CHA } \\
\text { augmentation group }\end{array}$} \\
\cline { 2 - 5 } & Number of implants & Site of implant & Number of implants & Site of implant \\
\hline 1 & 4 & $14,15,26,27$ & 3 & $14,15,16$ \\
2 & 4 & $14,15,25,26$ & 3 & $14,15,26$, \\
3 & 3 & $14,15,16$ & 2 & 15,26 \\
4 & 3 & $14,15,26$, & 2 & 25,26 \\
5 & 2 & 14,15 & 1 & 26 \\
6 & 2 & 15,26 & 2 & 15,26 \\
7 & 3 & $14,15,26$, & 2 & 15,26 \\
8 & 3 & $24,25,26$, & 2 & 25,26 \\
9 & 3 & $14,15,26$ & 2 & 26,26 \\
10 & 3 & $14,15,16$ & 1 & \\
\hline Total $=20$ & 30 & & 20 & \\
\hline
\end{tabular}


Table 2 a: Detailed biographic Data on the patient population, length of the healing period, changes of bone height in the augmented sinuses observed on CT scans, and radiographic peri-implant marginal bone levels at 1-year post-loading (CHA augmentation group):

\begin{tabular}{ccccccc}
\hline Age (years) & $\begin{array}{c}\text { Healing period } \\
\text { (month) }\end{array}$ & $\begin{array}{c}\text { Bone height } \\
\text { preoperative }(\mathrm{mm})\end{array}$ & $\begin{array}{c}\text { Bone height } \\
\text { postoperative }(\mathrm{mm})\end{array}$ & $\begin{array}{c}\text { Increase in } \\
\text { mineralized tissue } \\
\text { on CT (mm) }\end{array}$ & Marginal (mm) \\
\hline 1 & 63 & 12 & 6 & 12 & 6 & 1.7 \\
2 & 50 & 9 & 5 & 10 & 5 & 1 \\
3 & 45 & 11 & 5 & 9 & 4 & 1 \\
4 & 43 & 9 & 5 & 10 & 5 & 0.8 \\
5 & 32 & 9 & 6 & 9 & 3 & 0.9 \\
6 & 62 & 10 & 5 & 11 & 6 & 1.5 \\
7 & 30 & 11 & 6 & 9 & 3 & 1 \\
8 & 33 & 9 & 5 & 9 & 4 & 1 \\
9 & 39 & 9 & 6 & 10 & 4 & 0.7 \\
10 & 25 & 9 & 5 & 11 & 6 & 1.5 \\
\hline
\end{tabular}

Table 2 b: Data on the patient population, length of the healing period, changes of bone height in the augmented sinuses observed on CT scans, and radiographic peri-implant marginal bone levels at 1-year post-loading (CHA augmentation group):

\begin{tabular}{|c|c|c|c|c|c|c|}
\hline & Age (years) & $\begin{array}{l}\text { Healing period } \\
\text { (month) }\end{array}$ & $\begin{array}{c}\text { Bone height } \\
\text { preoperative }(\mathrm{mm})\end{array}$ & $\begin{array}{c}\text { Bone height } \\
\text { postoperative }(\mathrm{mm})\end{array}$ & $\begin{array}{l}\text { Increase in mineralized } \\
\text { tissue on } \mathrm{CT}(\mathrm{mm})\end{array}$ & Marginal (mm) \\
\hline Mean & 42.2 & 9.8 & $5.4^{1}$ & $10.0^{1}$ & 4.6 & 1.11 \\
\hline SD & 13.07 & 1.14 & 0.52 & 1.05 & 1.17 & 0.33 \\
\hline Max & 63 & 12 & 6 & 12 & 6 & 1.7 \\
\hline Min & 25 & 9 & 5 & 9 & 3 & 0.7 \\
\hline
\end{tabular}

1: $P<0.001$, analyzed by paired samples $\mathrm{t}$ test.

Table 3 a: Biographic Data on the patient population, length of the healing period, changes of bone height in the augmented sinuses observed on CT scans, and radiographic peri-implant marginal bone levels at 1-year post-loading (b-TCP augmentation group):

\begin{tabular}{ccccccc}
\hline Age (years) & $\begin{array}{c}\text { Healing period } \\
\text { (month) }\end{array}$ & $\begin{array}{c}\text { Bone height } \\
\text { preoperative }(\mathrm{mm})\end{array}$ & $\begin{array}{c}\text { Bone height } \\
\text { postoperative }(\mathrm{mm})\end{array}$ & $\begin{array}{c}\text { Increase in mineralized } \\
\text { tissue on CT }(\mathrm{mm})\end{array}$ & Marginal (mm) \\
\hline 1 & 63 & 12 & 6 & 14 & 8 & 1.5 \\
2 & 40 & 9 & 5 & 13 & 8 & 1 \\
3 & 55 & 11 & 5 & 12 & 7 & 1 \\
4 & 33 & 9 & 5 & 13 & 8 & 0.8 \\
5 & 42 & 9 & 6 & 12 & 6 & 0.9 \\
6 & 52 & 10 & 5 & 11 & 6 & 1.5 \\
7 & 40 & 11 & 5 & 13 & 8 & 1 \\
8 & 33 & 9 & 5 & 12 & 7 & 1 \\
9 & 31 & 9 & 6 & 12 & 6 & 0.7 \\
10 & 25 & 9 & 5 & 13 & 8 & 1.5 \\
\hline
\end{tabular}


Table 3 b: Data on the patient population, length of the healing period, changes of bone height in the augmented sinuses observed on CT scans, and radiographic peri-implant marginal bone levels at 1 year post-loading (b TCP augmentation group):

\begin{tabular}{lcccccc}
\hline Age (years) & $\begin{array}{c}\text { Healing period } \\
(\text { month })\end{array}$ & $\begin{array}{c}\text { Bone height } \\
\text { preoperative }(\mathrm{mm})\end{array}$ & $\begin{array}{c}\text { Bone height } \\
\text { postoperative }(\mathrm{mm})\end{array}$ & $\begin{array}{c}\text { Increase in mineralized } \\
\text { tissue on CT }(\mathrm{mm})\end{array}$ & Marginal \\
\hline Mean & 41.4 & 9.8 & $5.3^{1}$ & $12.4^{1}$ & 7.1 & 1.09 \\
SD & 11.96 & 1.14 & 0.48 & 0.97 & 1.1 & 0.29 \\
Max & 63 & 12 & 6 & 14 & 8 & 1.5 \\
Min & 25 & 9 & 5 & 11 & 5 & 0.5 \\
\hline
\end{tabular}

1: $P<0.001$, analyzed by paired samples $t$ test.

Table 3 c: Comparing data on the patient population, length of the healing period, changes of bone height in the augmented sinuses observed on CT scans, and radiographic peri-implant marginal bone levels at 1-year post-loading (both group):

\begin{tabular}{lccc}
\hline \multicolumn{1}{c}{ Variables } & CHA study group & b-TCP study group & $P$-value \\
\hline Age (years) & $42.2 \pm 13.07$ & $41.4 \pm 11.96$ & 0.888 \\
Healing period (month) & $9.8 \pm 1.14$ & $9.8 \pm 1.14$ & 1.000 \\
Bone height preoperative (mm) & $5.4 \pm 0.52$ & $5.3 \pm 0.48$ & 0.660 \\
Bone height postoperative (mm) & $10.0 \pm 1.05$ & $12.4 \pm 0.97$ & $<0.001^{*}$ \\
Increase in mineralized tissue on & $4.6 \pm 1.17$ & $7.1 \pm 1.1$ & $<0.001^{*}$ \\
CT (mm) & & & \\
Marginal & $1.11 \pm 0.33$ & $1.09 \pm 0.29$ & 0.890 \\
\hline
\end{tabular}

Values present as mean $\pm S D$ and analyzed by Independent samples t test.

*: Significant.

Table 4 a: Biographic Data on the patient population, changes of bone density in the augmented sinuses observed on CT scans, preoperatively and at 9-month post-augmentation:

\begin{tabular}{|c|c|c|c|c|c|c|}
\hline & \multicolumn{3}{|c|}{ CHA study group } & \multicolumn{3}{|c|}{ b-TCP study group } \\
\hline & \multirow[t]{2}{*}{$\begin{array}{l}\text { Initial ridge density } \\
\text { preoperative }(\mathrm{HU})\end{array}$} & \multicolumn{2}{|c|}{$\begin{array}{c}\text { Augmented area density } \\
\text { post-operative }(\mathrm{HU})\end{array}$} & \multirow{2}{*}{$\begin{array}{l}\begin{array}{l}\text { Initial ridge density } \\
\text { preoperative }(\mathrm{HU})\end{array} \\
\mathrm{V}\end{array}$} & \multicolumn{2}{|c|}{$\begin{array}{l}\text { Augmented area density } \\
\text { post-operative }(\mathrm{HU})\end{array}$} \\
\hline & & Immediate & 9 months after & & Immediate & 9 months after \\
\hline 1 & 800 & 700 & 900 & 800 & 1000 & 1400 \\
\hline 2 & 800 & 600 & 750 & 1100 & 1000 & 1200 \\
\hline 3 & 800 & 550 & 700 & 700 & 900 & 1300 \\
\hline 4 & 750 & 650 & 800 & 600 & 800 & 1100 \\
\hline 5 & 650 & 450 & 600 & 650 & 750 & 950 \\
\hline 6 & 600 & 500 & 650 & 600 & 900 & 1100 \\
\hline 7 & 600 & 400 & 550 & 650 & 900 & 1200 \\
\hline 8 & 700 & 450 & 600 & 700 & 800 & 1300 \\
\hline 9 & 600 & 450 & 600 & 600 & 950 & 1200 \\
\hline 10 & 600 & 400 & 550 & 750 & 800 & 950 \\
\hline
\end{tabular}


Table 4 b: Data on the patient population, changes of bone density in the augmented sinuses observed on CT scans, preoperatively and at 9-month post-augmentation:

\begin{tabular}{|c|c|c|c|c|c|c|}
\hline \multicolumn{4}{|c|}{ CHA study group } & \multicolumn{3}{|c|}{ b-TCP study group } \\
\hline & \multirow{2}{*}{$\begin{array}{l}\text { Initial ridge density } \\
\text { preoperative }(\mathrm{HU})\end{array}$} & \multicolumn{2}{|c|}{$\begin{array}{l}\text { Augmented area density } \\
\text { post-operative }(\mathrm{HU})\end{array}$} & \multirow{2}{*}{$\begin{array}{l}\text { Initial ridge density } \\
\text { preoperative } \\
\text { (HU) }\end{array}$} & \multicolumn{2}{|c|}{$\begin{array}{l}\text { Augmented area density } \\
\text { post-operative }(\mathrm{HU})\end{array}$} \\
\hline & & Immediate & 9 months after & & Immediate & 9 months after \\
\hline Mean & $690^{1}$ & $515^{*}$ & $6701 *$ & $715^{2}$ & $880^{\#}$ & $1170^{2 \#}$ \\
\hline SD & 90.68 & 105.54 & 115.95 & 151.01 & 88.82 & 147.57 \\
\hline $\operatorname{Max}$ & 800 & 700 & 900 & 1100 & 1000 & 1400 \\
\hline Min & 600 & 400 & 550 & 600 & 750 & 950 \\
\hline
\end{tabular}

CT scans were performed immediately and 9 months after insertion and showed dense mineralized material in the sinuses surrounding the implants. In many cases, it has been difficult to delineate the boundary between the original sinus floor and the newly formed tissue. The initial height of the bone under the sinus floor, measured using the original $\mathrm{CT}$ images, varied between 5 and 6 $\mathrm{mm}$ with an average of $5.4 \pm 0.52 \mathrm{~mm}$ in the CHA group and $5.3 \pm 0.48$ in b-TCP study group. In the postoperative evaluation of the second CT scan 9 months after the operation, the height of the $\mathrm{CHA}$ radiopaque tissue increased significantly $(P<0.001)$ to $9-12 \mathrm{~mm}$ with an average increase of $4.6 \pm 1.17 \mathrm{~mm}$ (Figure 5), while the height of the radiopaque b-TCP tissue increased to 11-14 $\mathrm{mm}$ with a significant average increase of $7.1 \pm 1.1 \mathrm{~mm}(P<0.001)$ (Figures 6 and 7$)$.

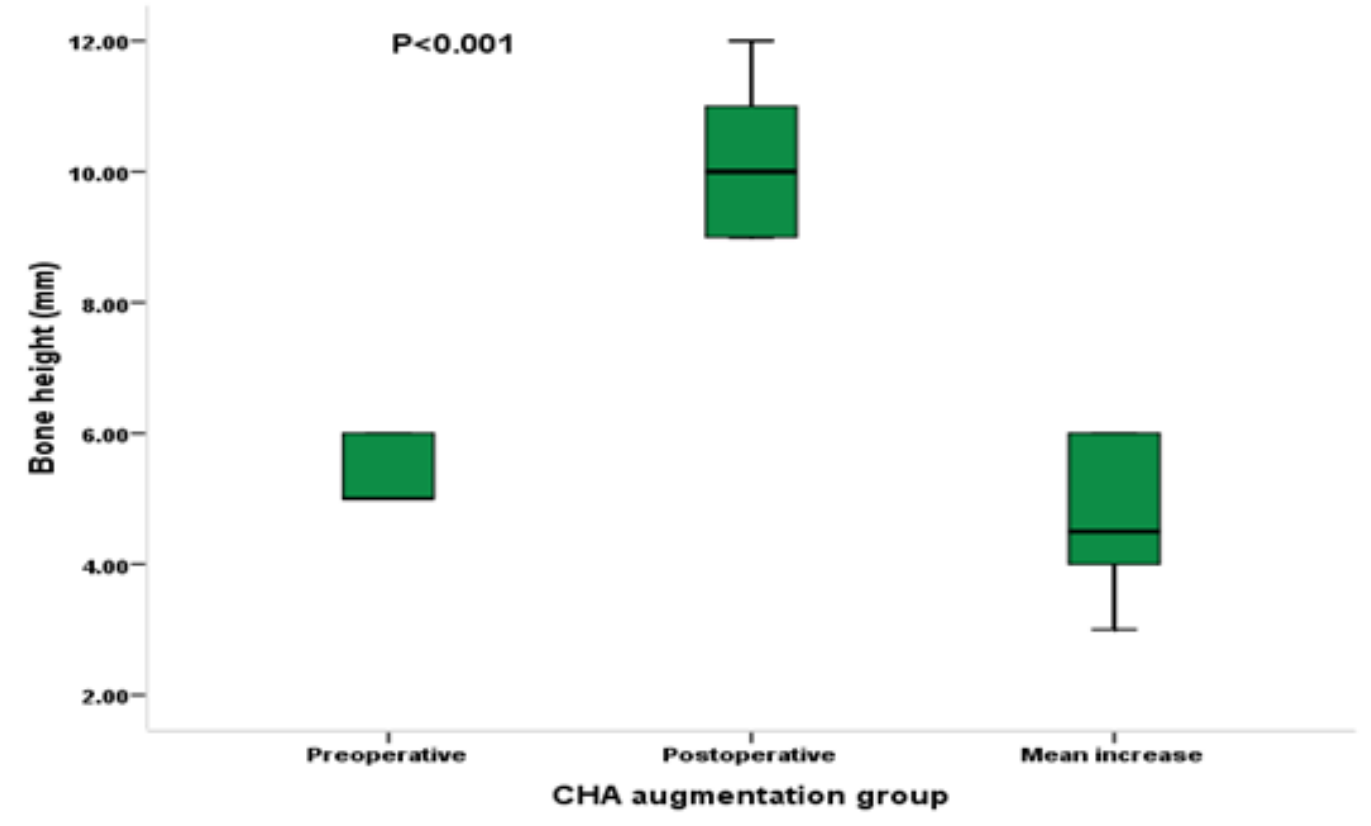

Figure 5: Change in the height of radiopaque tissues pre and postoperative in CHA augmentation group. 


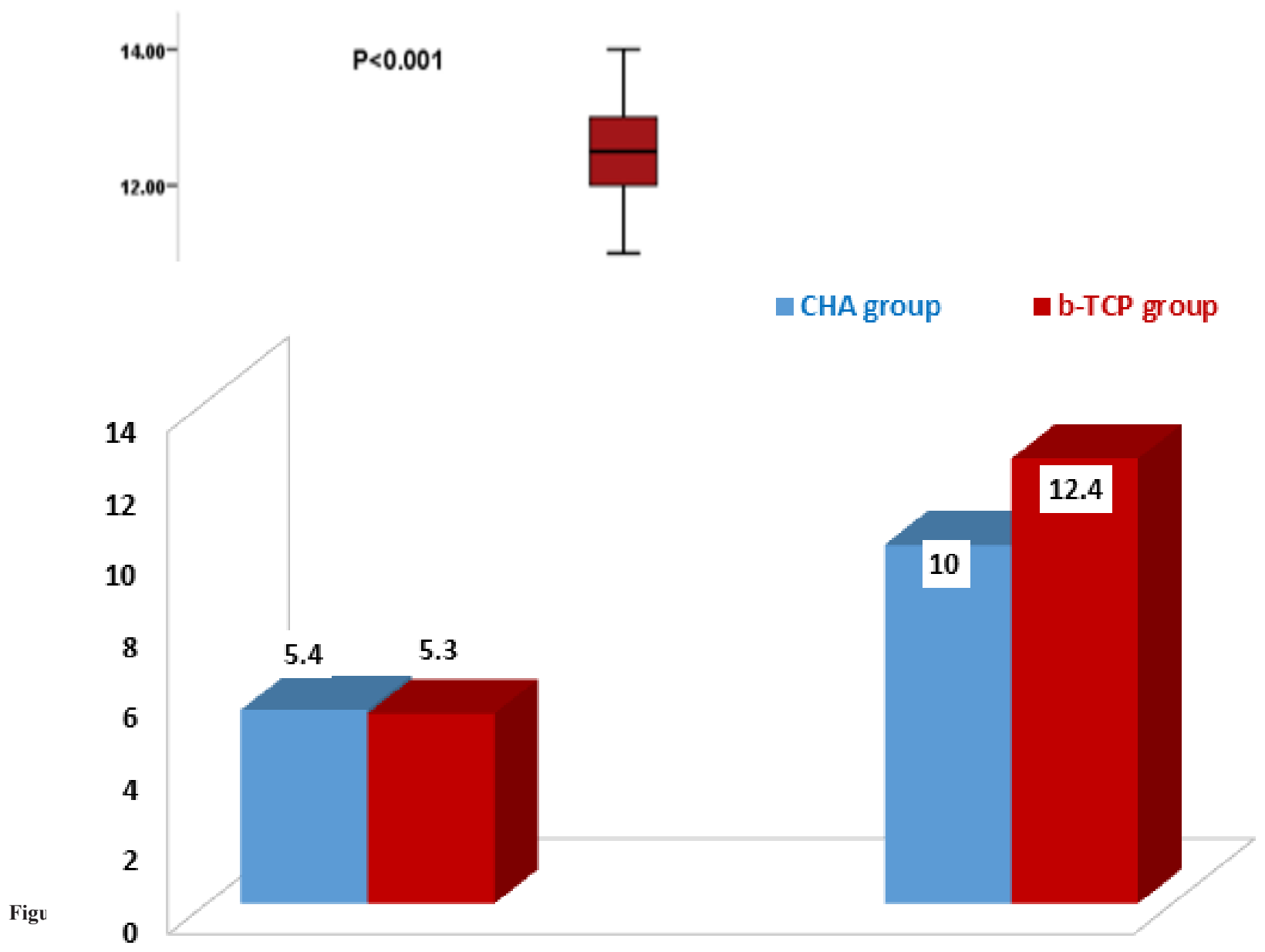

Figure 7: Bone height preoperative and 9 months after augmentation in both groups

\section{Changes in bone density of the grafts}

\section{GROUP 1}

The CHA xenograft showed an increase in bone density in all patients. The average density of CHA grafts increased significantly from an average of $515 \mathrm{HU}( \pm 105.54 \mathrm{HU})$ immediately after the increase to $670 \mathrm{HU}( \pm 115.95 \mathrm{HU})$ 9 month after the increase $(P<0.001)$.

The comparison of the bone density in the area of interest preoperatively and 9 months after the increase showed a bone density that was not significantly preoperatively below an average of $690 \mathrm{HU}( \pm 90.68 \mathrm{HU})$ to $670 \mathrm{HU}$ ( $\pm 115.95 \mathrm{HU}) 9$ months after augmentation surgery. The average percentage of the density of the grafted area after 9 months compared to the initial density of the alveolar ridge at the implantation site was $-2.89 \%$ with no significant decrease $(P=0.373)$ (Figure 8$)$.

\section{GROUP 2}

Radiological analysis of the b-TCP graft showed a higher bone density in all patients. The average density of the b-TCP graft increased significantly from an average of $880 \mathrm{HU}( \pm 88.82 \mathrm{HU})$ immediately after the antral grafting to $1170 \mathrm{HU}( \pm 147.57 \mathrm{HU}) 9$ months post operatively $(P<0.001)$.

The comparison of the bone density in the area of interest preoperatively and 9 months after the increase showed a significantly higher bone density from an average of $715 \mathrm{HU}( \pm 151.01 \mathrm{HU})$ preoperatively to $1170 \mathrm{HU}( \pm 147,57 \mathrm{HU}) 9$ months post operatively. The average percentage of the density of the grafted area after 9 months compared to the initial density of the alveolar ridge at the implantation site was $63.6 \%$ with a significant increase $(P<0.001)$ (Figure 8). 


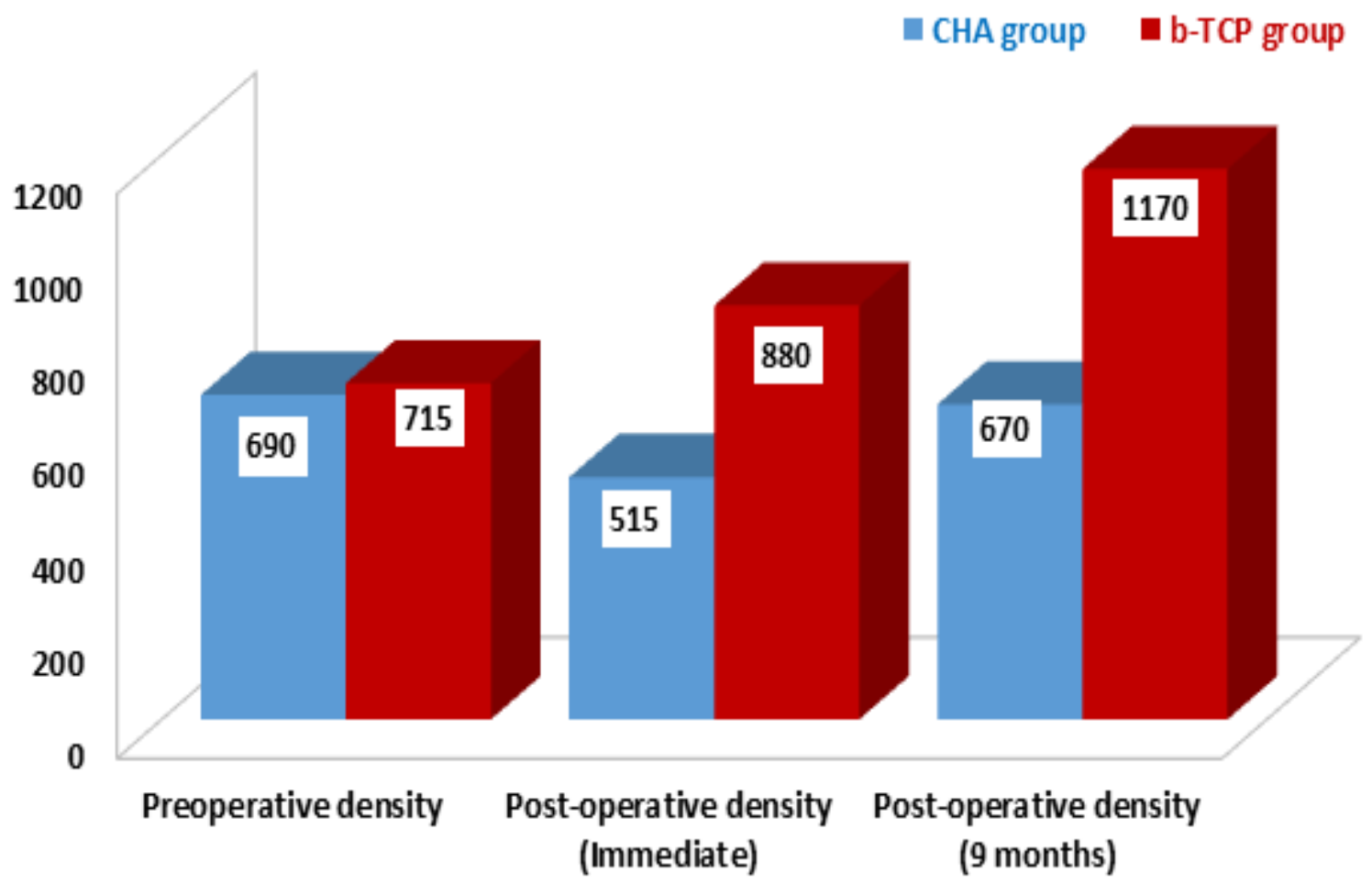

Figure 8: Augmented area density preoperative, immediately and 9 months after augmentation in both groups.

\section{DISCUSSION}

Although many studies recommended the two-step procedure for patients with an alveolar bone height of $5 \mathrm{~mm}$ or less in the posterior maxilla ${ }^{[29]}$, this study evaluated the performance of CHA compared to b-TCP bone grafts in one-step sinus augmentation with simultaneous Implant insertion in patients with a bone height of 5 to $6 \mathrm{~mm}$ before the transplant. The one-step approach saves the patient from having to perform a second operation, and if done by experienced surgeons, it is predictable. The results of this research suggest that $\mathrm{CHA}$ bone grafting and b-TCP provide adequate bone quality and volume for predictable simultaneous implantation in these patients and candidates for use as an alternative to autogenous and allogeneic bone grafts.

With regard to the low ridge height of $5 \mathrm{~mm}$, Peleg et al. ${ }^{[30]}$ stated that the one-step procedure for patients with only $3 \mathrm{~mm}$ height of the alveolar bone before antral grafting could be carried out using implants coated with hydroxyapatite and autogenous bone. Then, the onestep, of low ridge height of $5-\mathrm{mm}$ crest protocol used in this study offers the advantages of superior predictability, reducing the number of operations and the time required to complete the functioning implants.
Ellegaard et al. ${ }^{[31]}$ questioned the need for sinus augmentation procedures without graft material. The authors reported a good success rate with 38 implants that were used in the sinus lift procedure without graft material in the premolar / molar areas with a vertical bone height of up to $3 \mathrm{~mm}$. However, the small number of implants in this study compared to the highest number (50 implants) in the present study did not provide solid evidence of the superiority of this technique.

In their conclusions, the authors themselves emphasized that this technique should only be used in patients with high demands on oral hygiene, since the relatively short implants increases the risk of early failure due to inflammation and marginal bone loss.

Various clinical studies and case reports ${ }^{[32}$ - 34] have shown that although maxillary sinus grafting with different graft materials can be clinically successful. Its familiar to emphasize the autogenous bone still provides the best osteogenic potential and bone biomechanical properties.

However, the quantitative limitations of autogenous bone extracted from intraoral sites often force the doctor to look for other types of grafts to get the appropriate amount of graft material. 
Allografts used as an alternative to autografts have several problems, mainly related to the late reabsorption of freeze-dried dehydrated bone particles, variable inductive properties, and the potential for disease transmission ${ }^{[33]}$ The alternatives to autogenous and allogeneic bone grafts are xenogeneic CHA and Alloplastic b-TCP, which were used in the present study.

Because doctors are in daily contact with bone substitute materials and are more interested in the clinical success, durability and reliability of the products they use than in scientific details, such as cellular reactions. Compared to histological and histomorphometric analysis, the present study, according to the idea of radiological analysis, required less effort for both the researcher and the patient, since it is benefits as "non-invasive " follow up procedure from technical support.

However, it should be mentioned that detailed conclusions on cellular responses to different biomaterials can only be drawn by histological and histomorphometric analyzes, especially during the initial phase of the study, the histological analysis of biopsies remains important and will be no less relevant ${ }^{[35]}$.

The increase in bone density and ridge volume in both groups represents the increased reorganization of bone replacement materials with the newly formed bone and suggests that condensation processes or the loss of the liquid component causes the increased volume density. However, the evaluation of $\mathrm{CT}$ examinations cannot provide any objective information about the degradation or dehydration process.

A possible explanation for the fact that the volume and density appeared to increase, which was significantly higher in both groups 9 month post-operative (compared to the immediate postoperative increase) regardless of cellular reactions, is a combination of manual condensation of bone replacement material and increased dehydration of biomaterials after implantation with simultaneous growth of newly formed bone tissue in the intergranular space.

Compared to the percentage increase in the bone volume in the sinuses with different particulate graft materials, the results reported by several authors have shown great differences ${ }^{[32]}$. A study by Wheeler et al., found an increase in bone volume from $16.38 \%$ after 4 to 10 months of healing to $45.30 \%$ after 36 months of sinus grafting with porous alloplastic hydroxyapatite alone ${ }^{[36]}$, whereas in the present study a higher percentage of new bone formation in both groups of alloplastic CHA and b-TCP ( $85 \%$ and $133.9 \%$ on average) after 9 months of healing of the elevated sinus cavities.

Therefore, the radiologically examined amount and the changes in bone density in the present study were significantly different between the two groups. The maximum height and the increase in bone density increased in both groups, but more significantly in the b-TCP group instead of the CHA group during the 9-month observation period.

While many studies have shown biocompatible properties and promising osteogenic results, the use of CHA as a bone substitute and porous bone fill may be limited due to its inherent mechanical weakness and reduced biodegradation ${ }^{[37]}$. And this is an explanation for the increased increase in quantity and bone density in the CHA study group compared to the b-TCP group.

This is in line with the benefits of reporting on CHA as a bone graft, particularly in terms of its safety, biocompatibility and osteoconductivity. Therefore, CHA can be used as a bone replacement biomaterial in many clinical indications.

The methodology presented can be a reliable and adequate technique for analyzing the volume and density of the CHA and b-TCP bone graft for sinus augmentation with simultaneous implantation.

\section{CONCLUSION}

Despite the limited number of cases and short followup time in this clinical trial, it was concluded that the two graft materials had successful biocompatibility and osteoconductivity in sinus augmentation. However, B-TCP appears to be more effective than CHA in osteoconduction.

\section{CONFLICT OF INTEREST}

The authors declare no conflict of interest.

\section{REFERENCES}

1. Boyne PJ, James RA. Grafting of the maxillary sinus floor with autogenous marrow and bone. J Oral Surg. 1980; 38:613-616.

2. Tatum H. Maxillary and sinus implant reconstructions. Dent Clin North Am. 1986; 30:207-222.

3. Kurkcu M, Benlidayi ME, Cam B, et al. Anorganic bovine-derived hydroxyapatite vs $\beta$-tricalcium phosphate in sinus augmentation: a comparative histomorphometric study. J Oral Implantol. 2012; 38: 51926-.

4. Jensen SS, Shulman LB, Block MS, et al. Report of the sinus consensus conference of 1996. Int J Oral Maxillofac Implants 1998; 13:11-45.

5. Block MS, Kent JN. Sinus augmentation for dental implants: the use of autogenous bone. J Oral Maxillofac Surg. 1997; 55:1281- 1286. 
6. Moy PK, Lundgren S, Holmes RE. Maxillary sinus augmentation: histomorphometric analysis of graft materials for maxillary sinus floor augmentation. J Oral Maxillofac Surg. 1993; 51:857-862.

7. Pejrone G, Lorenzetti M, Mozzati M, et al. Sinus flooraugmentation with autogenous iliac boneblock grafts: a histological and histomorphometrical report on the twostep surgical technique. Int J Oral Maxillofac Surg. 2002; 31:383-388.

8. Younger EM, Chapman MW. Morbidity at bone graft donor sites. J Orthop Trauma 1989; 3:192195.

9. Kalk WWL, Raghoebar GM, Jansma J, et al. Morbidity from iliac crest bone harvesting. J Oral Maxillofac Surg. 1996; 54: 1424-1429.

10. Tadjoedin ES, de Lange GL, Lyaruu DM, et al. High concentrations of bioactive glass material (BioGran) vs. autogenous bone for sinus floor elevation. Clin Oral Implants Res. 2002; 13:428436.

11. Quinones $\mathrm{CR}$, Hürzeler $\mathrm{MB}$, Schüpbach $\mathrm{P}$, et al. Maxillary sinus augmentation using different grafting materials and osseointegrated dental implants in monkeys. Part II: evaluation of porous hydroxyapatite as a grafting material. Clin Oral Implants Res. 1997; 8: 487-496.

12. Szabo G, Suba Z, Hrabak K, et al. Autogenous bone versus beta tricalcium phosphate graft alone for bilateral sinus elevations (2- and 3-dimensional computed tomographic, histologic, and histomorphometric observations): preliminary results. Int J Oral Maxillofac Implants. 2001; 16:681-692.

13. Szabo G, Huys L, Coulthard P, et al. A prospective multicenter randomized clinical trial of autogenous bone versus b-tricalcium phosphate graft alone for bilateral sinus elevation: histologic and histomorphometric evaluation. Int $\mathrm{J}$ Oral Maxillofac Implants. 2005; 20:371-381.

14. Zerbo IR, Zijderveld SA, De Boer A. Histomorphometry of human sinus floor augmentation using a porous beta-tricalcium phosphate: a prospective study. Clin Oral Implants Res. 2004; 15: 724-732.

15. Zijderveld SA, Zerbo IR, van den Bergh $\mathrm{JP}$, et al. Maxillary sinus floor augmentation using a betatricalcium phosphate (Cerasorb) alone compared to autogenous bone grafts. Int $\mathrm{J}$ Oral Maxillofac Implants. 2005; 20:432-440.
16. Hürzeler MB, Quinones CR, Kirsch A. Maxillary sinus augmentation using different grafting materials and dental implants in monkeys. Part I. Evaluation of anorganic bovine-derived bone matrix. Clin Oral Implants Res. 1997 Dec; $8(6): 476-486$.

17. Valentini P, Abensur DJ. Maxillary sinus grafting with anorganic bovine bone: a clinical report of long-term results. Int J Oral Maxillofac Implants 2003; 18:556-560.

18. Yildırım M, Spiekermann H, Biesterfeld $\mathrm{S}$, et al. Maxillary sinus augmentation using xenogenic bone substitute material Bio-Oss in combination with venous blood: a histologic and histomorphometric study in humans. Clin Oral Implants Res. 2000; 11:217-229.

19. Haas R, Donath K, Fo“dinger M, et al. Bovine hydroxyapatite for maxillary sinus grafting: comparative histomorphometric findings in sheep. Clin Oral Implants Res. 1998; 9:107-116.

20. Sartori S, Silvestri M, Forni F, et al. Ten-year follow-up in a maxillary sinus augmentation using anorganic bovine bone (Bio-Oss): a case report with histomorphometric evaluation. Clin Oral Implants Res. 2003; 14: 369-372.

21. Benlidayi ME, Kurkcu M, Oz IA, et al. Comparison of two different forms of bovinederived hydroxyapatite in sinus augmentation and simultaneous implant placement: an experimental study. Int J Oral Maxillofac Implants 2009; 24:704-711.

22. Avila G, Neiva R, Misch CE. Clinical and histologic outcomes after the use of a novel allograft for maxillary sinus augmentation: a case series. Implant Dent 2010; 19:330-341.

23. Simunek A, Kopecka D, Somanathan RV, et al. Deproteinized bovine bone versus beta-tricalcium phosphate in sinus augmentation surgery: a comparative histologic and histomorphometric study. Int J Oral Maxillofac Implants. 2008; 23:935-942.

24. Berglundh T, Lindhe J. Healing around implants placed in bone defects treated with Bio-Oss: an experimental study in the dog. Clin Oral Implants Res. 1997; 8:117-124.

25. Hammerle CH, Olah AJ, Schmid J. The biological effect of natural bone mineral on bone formation on the rabbit skull. Clin Oral Implants Res. 1997; 8:198-207. 
26. Peetz M. Characterization of xenogenic bone material. In: Boyne PJ, Evensen L, eds. Osseous Reconstruction of the Maxilla and the Mandible: Surgical Techniques Using Titanium Mesh and Bone Mineral. Carol Stream, Ill: Quintessence; 1997; $87-100$.

27. Breitbart AS, Staffenberg DA, Thorne $\mathrm{CH}$, et al. Tricalcium phosphate and osteogenin: a bioactive onlay bone graft substitute. Plast Reconstr Surg. 1995; 96:699- 708 .

28. Buser D, Hoffmann B, Bernard JP, et al. Evaluation of filling materials in membrane protected bone defects: a comparative histomorphometric study in the mandible of miniature pigs. Clin Oral Implants Res. 1998; 9:137 - 150 .

29. Jensen J, Simonsen EK, Sindet PS. Reconstruction of the severely resorbed maxilla with bone grafting and osseointegrated implants: a preliminary report. J Oral and Maxillofac Surg.1990; 48: 27 - 32.

30. Peleg M, Mazor Z, Garg AK. Augmentation grafting of the maxillary sinus and simultaneous implant placement in patients with 3 to $5 \mathrm{~mm}$ of residual alveolar bone height. Int J Oral Maxillofac Implants. 1999; 14: 549-556.

31. Ellegaard B, Kølsen PJ., Baelum V. Implant therapy involving maxillary sinus lift in periodontally compromised patients. Clin Oral Implants Res. 1997; 8: $305-315$.
32. Hu“rzeler MB, Quinones CR, Kirsch A. Maxillary sinus augmentation using different grafting materials and dental implants in monkeys. Part III. Evaluation of autogenous bone combined with porous hydroxyapatite. Clin Oral Implants Res. 1997 Oct; 8(5): $401-411$.

33. Lorenzetti M, Mozzati M, Campanino PP, et al. Bone augmentation of the inferior floor of the maxillary sinus with autogenous bone or composite bone grafts: a histologic-histomorphometric preliminary report. Int J Oral Maxillofac Implants. 1998; 13: $69-76$.

34. Valentini $\mathrm{P}$, Abensur $\mathrm{D}$, Densari $\mathrm{D}$, et al. Histological evaluation of Bio-Oss A in a 2-stage sinus floor elevation and implantation procedure. A human case report. Clin Oral Implants Res.1998; 9: 59 - 64.

35. Lorenz J, Eichler K, Barbeck M. Volumetric analysis of bone substitute material performance within the human sinus cavity of former head and neck cancer patients: A prospective, randomized clinical trial. Ann Maxillofac Surg. 2016; 6:175 181.

36. Wheeler SL, Holmes RE, Calhoun CJ. Six-year clinical and histologic study of sinus-lift grafts. Int J Oral Maxillofac Implants .1996; 11: 26 - 34.

37. Damien E, Revell PA. Coralline hydroxyapatite bone graft substitute: A review of experimental studies and biomedical applications. J app biomat biomech 2004; 2: 65 - 73 . 